7. Reprod. Fert. (1973) 34, 191-196

\title{
THE CONCEPTION RATE OF EWES IN RELATION TO SPERM DOSE AND TIME OF INSEMINATION*
}

\author{
H. SCHINDLER AND D. AMIR \\ Agricultural Research Organization, The Volcani Center, \\ Bet Dagan, Israel
}

(Received 26th February 1973)

The effect of different sperm doses on the conception rate has been studied by Salamon (1962), Gancev (1963) and Kareta, Osikowski \& Wierzbowski (1966), but without relation to a possible effect of time of insemination. Jones, Martin \& Lapwood (1969) and Entwistle \& Martin (1972) studied the effect of restricted sperm doses $\left(100 \times 10^{6}\right.$ and $50 \times 10^{6}$ spermatozoa) and, by relating the results to vaginal mucus score, found that the highest conception rate occurred in ewes with a copious, clear or cloudy mucus at the time of insemination. On the other hand, in recent work in this laboratory (Amir \& Schindler, 1972), it was shown that with the use of 300 to $500 \times 10^{6}$ freshly ejaculated spermatozoa, single inseminations of ewes were of uniform and high efficiency almost throughout oestrus. The present study was undertaken in order to investigate the possibility that the time range for obtaining maximal results may be more limited with reduced sperm numbers. The stages of oestrus were defined in terms of time intervals after its onset or before its end, since the mucus score was only a rough guide for the determination of the stage of oestrus (Schindler \& Amir, 1972).

In the first experiment, a total of 206 cycling, non-lactating Awassi and German Mutton Merino ewes were inseminated. The onset and duration of standing heat were determined by teasing with aproned rams in small groups for $30 \mathrm{~min}$ at 8-hr intervals, under the close supervision of the herdsman. Ewes in oestrus were immediately withdrawn and teasing was continued at 8-hr intervals until after the end of heat, when they were returned to the flock. This procedure ensured equal exposure of all ewes to the rams and also made it possible to relate the insemination results to the end of oestrus.

Semen was collected with an artificial vagina from fourteen rams in a random sequence. Only ejaculates with strong wave motion and a minimum concentration of $3.5 \times 10^{9}$ spermatozoa $/ \mathrm{ml}$ were used. The semen was immediately diluted at $30^{\circ} \mathrm{C}$ with reconstituted skimmed milk according to the method of Colas, Dauzier, Courot, Ortavant \& Signoret (1968). The dilution ratio was adjusted for each ejaculate so as to provide $800 \times 10^{6}$ spermatozoa $/ \mathrm{ml}$. The diluted semen was kept at 25 to $30^{\circ} \mathrm{C}$ until insemination, which was carried out within $1 \mathrm{hr}$ of ejaculation.

* Contribution from The Volcani Center, Agricultural Research Organization, Bet Dagan, Israel. 1973 Series, No. 104-E. 


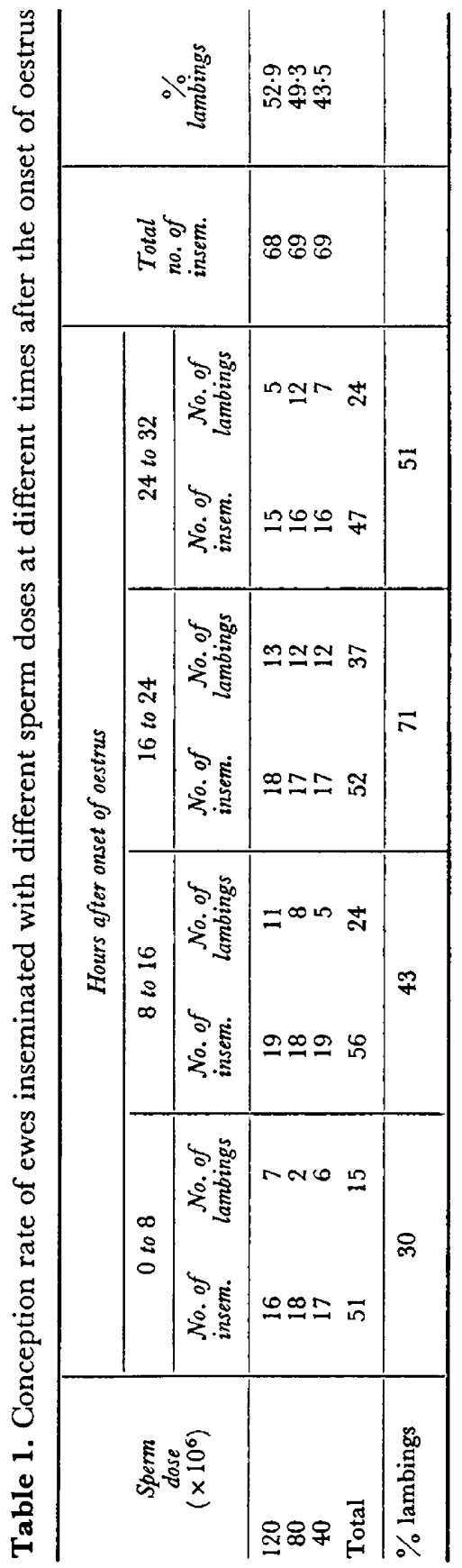




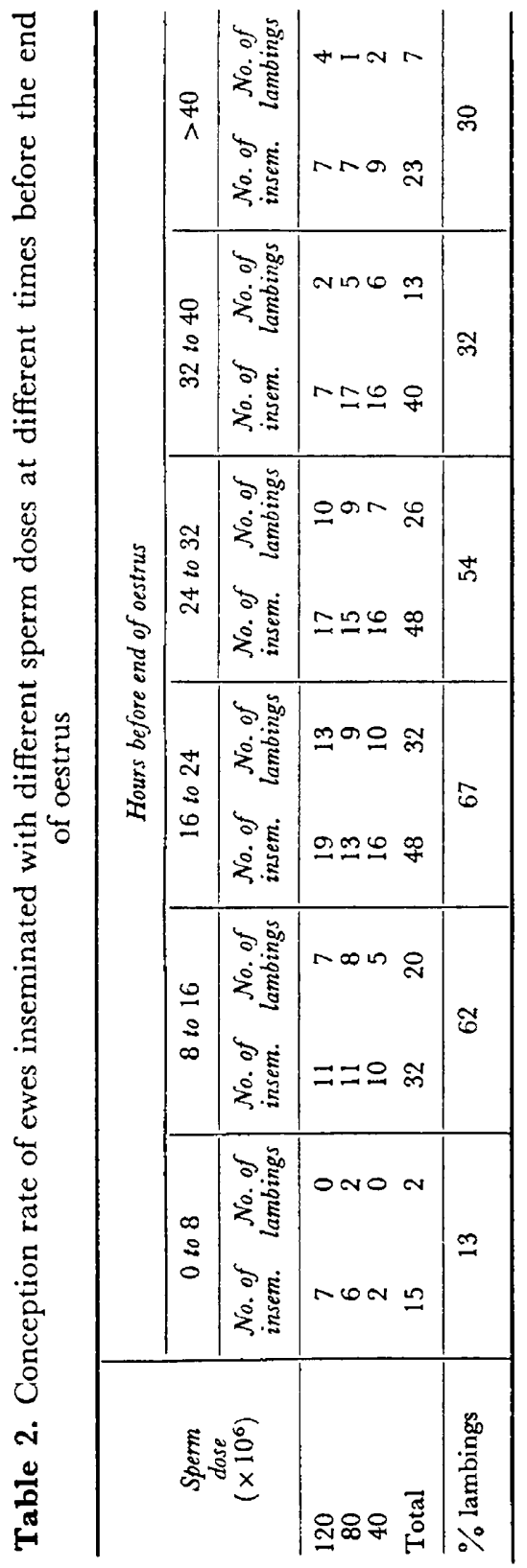


Each ewe received a single insemination at 08.00 hours, immediately after the morning teasing. At that time, the ewes were at one of the following stages after the onset of heat: 0 to 8,8 to 16,16 to 24 or 24 to $32 \mathrm{hr}$. Ewes from each group were randomly assigned to one of the following semen doses: $0.05 \mathrm{ml}$ $\left(40 \times 10^{6}\right.$ spermatozoa $), 0.10 \mathrm{ml}\left(80 \times 10^{6}\right.$ spermatozoa $)$ or $0.15 \mathrm{ml}\left(120 \times 10^{6}\right.$ spermatozoa).

For the second experiment, a total of 132 cycling, dry or milking Awassi ewes were used. They were teased at $12-\mathrm{hr}$ intervals and a single insemination was performed $12 \mathrm{hr}$ after oestrus had been detected, i.e. between 12 and $24 \mathrm{hr}$ after its onset. The preparation of the semen, which was collected from sixteen rams in random sequence, and the semen doses applied were the same as in the first experiment.

Chi-squared analysis was applied to the experimental results.

The results of the first experiment are presented in Tables 1 and 2. From Table 1, it can be seen that a high conception rate was limited to inseminations performed 16 to $24 \mathrm{hr}$ after the onset of oestrus. Inseminations performed earlier or later gave lower conception rates but the difference was statistically significant only for the results from the earlier inseminations.

When the times of insemination were related to the end of oestrus (Table 2), the best results were obtained from those inseminations performed between 8 and $24 \mathrm{hr}$, and intermediate results from those between 24 and $32 \mathrm{hr}$, before the end of oestrus. Inseminations performed earlier or later resulted in lower and statistically different conception rates.

The conception rates obtained from the three sperm doses (Table 1) decreased with decreasing sperm numbers but the differences were not statistically significant for the overall results or for the results at different stages of oestrus.

The insemination time in the second experiment (12 to $24 \mathrm{hr}$ after the onset of oestrus) was chosen so as to overlap the period found to be optimum in the first experiment ( 16 to $24 \mathrm{hr}$ after onset of oestrus), and feasible under farm flock conditions. The conception rates obtained with $120 \times 10^{6}$ (fortyone ewes), $80 \times 10^{6}$ (forty-six ewes) and $40 \times 10^{6}$ (forty-five ewes) spermatozoa were $68.3 \%, 67.4 \%$ and $55.5 \%$, respectively, i.e. similar to those in the first experiment at that stage of oestrus. The differences between the conception rates were not statistically significant.

The results of the first experiment showed that highest conception rates were obtained when inseminations were performed 8 to $24 \mathrm{hr}$ before the end of oestrus. This result is consistent with those of Mattner (1963), Quinlivan \& Robinson (1967, 1969) and Lang \& Oh (1970), who found that 16 to $24 \mathrm{hr}$ after mating or insemination, the accumulation in the oviduct of spermatozoa which are gradually released from the cervical reservoir (Quinlan, Mare \& Roux, 1933; Mattner, 1963, 1966) is at a maximum. When restricted sperm doses are used, inseminations carried out too early result in exhaustion of the sperm reserve before ovulation has taken place, which coincides, on average, with the end of oestrus in sheep (McKenzie \& Terrill, 1937; Schindler \& Amir, 1972). If insemination is too late, ovulation will occur before an adequate number of spermatozoa has accumulated at the fertilization site. With the use of large sperm doses, the time of insemination appears to be less critical (Amir 
\& Schindler, 1972), apparently because the sperm supply at the fertilization site becomes adequate, irrespective of the length of the period from semen deposition to ovulation. The necessity for correct timing when inseminating with reduced sperm numbers or stored semen is also indicated by the results of Salamon \& Lightfoot (1970) and Salamon (1971), who showed that inseminations with frozen semen carried out 15 to $25 \mathrm{hr}$ after the onset of oestrus were more efficient than those carried out 1 to $15 \mathrm{hr}$ after the onset of oestrus.

From the results of inseminations with restricted sperm doses, conclusions can be drawn regarding artificial breeding management of ewes under feed lot or farm flock conditions. When the average duration of oestrus is $36 \mathrm{hr}$ and the time of onset is not centered around any particular time of day, as in our experimental flocks (Schindler \& Amir, 1972), detection of the ewes in heat at 12-hr intervals and insemination $12 \mathrm{hr}$ later would ensure a maximal conception rate.

This research was financed in part by a grant made by the United States Department of Agriculture, under P.L. 480. The authors are indebted to Mr Y. Dimmerman for his assistance.

\section{REFERENCES}

Amir, D. \& Schindler, H. (1972) The conception rate of ewes after artificial insemination at different times during oestrus. F. Reprod. Fert. 28, 261.

Colas, G., Dauzier, L., Courot, M., Ortavant, R. \& Signoret, J. P. (1968) Résultats obtenus au cours de l'étude de queiques facteurs importants de l'insémination artificielle ovine. Annls Zootech. 17, 47.

ENTWISTLE, K. W. \& MARTIN, I. G. A. (1972) Effects of the number of spermatozoa and of volume of diluted semen on fertility in the ewe. Aust. 7. agric. Res. 23, 467.

Gancev, T. (1963) Insemination of ewes with different numbers of spermatozoa. Izv. Inst. Biol. Patol. Razmnozhav selskostop. Zhivot. 4, 97. (Anim. Breed. Abstr. 34, 411.)

Jones, R. G., Martin, I. C. A. \& Lapwood, K. R. (1969) Studies of the artificial insemination of sheep: the effects on fertility of diluting ram semen, stage of oestrus of the ewe at insemination, and injection of synthetic oxytocin. Aust. F. agric. Res. 20, 141.

Kareta, W., OsixowsKI, M. \& WierzBowski, S. (1966) Artificial insemination of ewes at ram evaluation stations. Medycyna wet. 22, 342. (Anim. Breed. Abstr. 36, Abstr. No. 1613.)

LANG, D. R. \& OH, Y. K. (1970) Distribution of spermatozoa in the reproductive tract of the Romney ewe. $\mathcal{N} . Z$. Jl agric. Res. 13, 157.

MaKenzie, F. F. \& Terrill, C. E. (1937) Estrus, ovulation, and related phenomena in the ewe. Res. Bull. Mo. agric. Exp. Stn. 264.

Mattner, P. E. (1963) Spermatozoa in the genital tract of the ewe. II. Distribution after coitus. Aust. 7. biol. Sci. 16, 688 .

MAtTnER, P. E. (1966) Formation and retention of the spermatozoa reservoir in the cervix of the ruminant. Nature, Lond. 212, 1479.

Quinlan, J., MARE, G. S. \& Roux, L. L. (1933) A study of the duration of motility of spermatozoa in the different regions of the reproductive tract of the Merino ewe. Ondersteport F. vet. Sci. Anim. Ind. 1, 135.

Quintrvan, T. D. \& Robinson, T. J. (1967) The number of spermatozoa in the Fallopian tubes of ewes at intervals after artificial insemination following withdrawal of SC-9880-impregnated intravaginal sponges. In: The Control of the Ovarian Gycle in the Sheep, p. 177. Ed. T. J. Robinson. Sydney University Press.

Quinlivan, T. D. \& Robinson, T. J. (1969) Numbers of spermatozoa in the genital tract after artificial insemination of progestagen-treated ewes. J. Reprod. Fert. 19, 73.

Salamon, S. (1962) Studies on the artificial insemination of Merino sheep. III. The effect of frequent ejaculation on semen characteristics and fertilizing capacity. Aust. F. agric. Res. 13, 1137. 
Salamon, S. (1971) Fertility of ram spermatozoa following pellet freezing on dry ice at -79 and $-140^{\circ}$ C. Aust. 7. biol. Sci. 24, 183.

Salamon, S. \& Lightroot, R. J. (1970) Fertility of ram spermatozoa frozen by the pellet method. III. The effects of insemination technique, oxytocin and relaxin on lambing. F. Reprod. Fert. 22, 409.

Schindler, H. \& Amir, D. (1972) Length of oestrus, duration of phenomena related to oestrus, and ovulation time in the local fat-tailed Awassi ewe. J. agric. Sci., Camb. 78, 151. 